\title{
Frequency of hematologic malignancies in the population of Arica, Chile
}

\author{
GLORIA BAEZA PÉREZ ${ }^{1}$, GLORIA M. CALAF ${ }^{2,3}$, MARÍA TERESA MONTALVO VILLALBA ${ }^{4}$, \\ KATHERINE SALGADO PRIETO ${ }^{4}$ and FRESIA CABA BURGOS ${ }^{5}$
}

\author{
${ }^{1}$ Laboratorio Clínico de Urgencias, Hospital Regional de Arica Dr. Juan Noé Crevani; \\ ${ }^{2}$ Instituto de Alta Investigación, Universidad de Tarapacá, Arica 1000000, Chile; ${ }^{3}$ Center for Radiological Research, \\ Columbia University Medical Center, New York, NY 10032, USA; ${ }^{4}$ Facultad de Ciencias de la Salud, \\ Universidad de Tarapacá, Arica 1000000; ${ }^{5}$ Facultad de Salud, Universidad Bernardo O'Higgins, Santiago 8320000, Chile
}

Received November 5, 2018; Accepted June 28, 2019

DOI: $10.3892 / 01.2019 .10858$

\begin{abstract}
Hematologic diseases are a heterogeneous group of malignancies that affect people worldwide such as leukemia, lymphoma and multiple myelomas. The aim of this study was to characterize the frequency of hematological diseases in the population of Arica, Chile $\left(18^{\circ} \mathrm{S}, 70^{\circ} \mathrm{W}\right)$, between 2011 and 2014. A total of 108 cases of hematologic malignancies were registered at Dr. Juan Noé Crevani Regional Hospital in this period; 40 male and 52 female cases were included in this retrospective and descriptive analysis. The overall median age at diagnosis for hematological malignancies was 59 years (range, 17 to 96 years). The results indicated that the frequency of hematological diseases such as non-Hodgkin lymphoma and leukemia was not associated with sex, ethnicity and type of disease. However, in 2012 there was an increased number of cases of Hodgkin lymphoma compared with any other year in the study, whereas the number of multiple myeloma cases decreased between 2011 and 2014 . No significant differences were observed among different types of disease, nor among the types of leukemia. However, when intervals of age were considered, it was revealed that patients $>75$ years had the highest incidence of hematological malignancies, mainly multiple myeloma, compared with other age groups. However, young adults were more commonly diagnosed with Hodgkin lymphoma than other
\end{abstract}

Correspondence to: Dr Gloria M. Calaf, Instituto de Alta Investigación, Universidad de Tarapacá, Calle Antofagasta 1520, Arica 1000000, Chile

E-mail: gmc24@cumc.columbia.edu

Abbreviations: ALL, acute lymphoblastic leukemia; AML, acute myeloid leukemia; CLL, chronic lymphocytic leukemia; CML, chronic myeloid leukemia; HL, Hodgkin lymphoma; HM, hematological malignancy; MM, multiple myeloma; NHL, non-Hodgkin lymphoma

Key words: leukemia, Hodgkin lymphoma, non-Hodgkin lymphoma, multiple myeloma, frequency, hematologic diseases disease types. A non-significant difference was observed in leukemia between 2011 and 2014 when sex was taken into consideration, in which the incidence rate was higher in females compared with males. Hodgkin lymphoma was most commonly at stage II and non-Hodgkin lymphoma was most commonly at stage IV. No significant differences were observed between the nodal and extranodal type, mixed cellularity and nodular sclerosis or in the morphology of non-Hodgkin lymphoma cell type. Overall, there was a decrease in the frequency of hematological malignancies between 2011 and 2014, but no significant differences were observed in males or females. This study provided for the first time the pattern and distribution of hematological diseases in Arica, Chile.

\section{Introduction}

Cancer is one of the main causes of mortality worldwide; according to the World Health Organization, cancer caused $\sim 8.2$ million deaths in 2012 (1). Cancer that develops from blood cells is termed neoplastic hematological malignancy (HM). HMs are a heterogeneous group of diseases of diverse incidence, prognosis and etiology that arise from malignant transformation of cells from the bone marrow or the lymphatic system $(2,3)$. There are two major groups of HM according to their cell lineage: Myeloid and lymphoid $(4,5)$. Lymphoid neoplasms are a varied group that includes non-Hodgkin lymphoma (NHL), Hodgkin lymphoma (HL), leukemia and multiple myeloma (MM) (6).

According to the Health and Information Statistics Department of Chile (DEIS) (2013), there were 94,985 national deaths registered in 2011; among those, 24,582 (25.88\%) were malignant tumor-related deaths (incidence rate, 142.52 per 100,000 inhabitants) (7). Tumors of the hematopoietic and lymphatic system exhibited a national mortality rate of 10.3 per 100,000 inhabitants in 2011 (7), where leukemia accounted for 3.77, HL 0.32, NHL 3.57 and MM 2.49 deaths per 100,000 inhabitants (8). In 2013 cancer causes $24.6 \%$ of the total deaths in Arica (9). Tumors of the hematopoietic and lymphatic systems exhibited a mortality rate of 12.0 per 100,000 inhabitants in this region (7), where leukemia, NHL 
and MM accounted for incidence rates of 3.82, 5.5 and 2.73 per 100,000 inhabitants, respectively (8).

Classification of acute leukemia is based on whether leukemic cells are of myeloid or lymphoid lineage (10). Belson et al (11) indicated that leukemia could be divided into four main types according to the pathological and clinical traits: Acute lymphoblastic leukemia (ALL), acute myeloid leukemia (AML), chronic lymphocytic leukemia (CLL) and chronic myeloid leukemia (CML). These authors also stated that in acute leukemia, the abnormal blood cells are immature and unable to serve normal functions. In chronic leukemia, most cells serve normal functions, and the number of abnormal white blood cells in acute leukemia increases faster than in chronic leukemia, and thus, acute leukemia is more deleterious (11). AML is a type of leukemia that affects the myeloid line of blood cells, whereas ALL targets the lymphoid line of blood cells (12).

Arica is a small city in the north of Chile. According to DEIS, the region had a population of 181,402 inhabitants in 2012; the population was mainly urban ( $90 \%$ vs. $10 \%$ rural). A total of 87,363 inhabitants were male and 94,039 female (13). Since there are few studies related to the epidemiological characterization of patients with hematological cancer in Chile, the aim of this study was to identify the distribution, frequency and features of HM in patients admitted to Dr. Juan Noé Crevani Regional Hospital of Arica between 2011 and 2014.

\section{Materials and methods}

Patients. This present retrospective study was based on the incidence of hematological malignancies that were registered at Dr. Juan Noé Crevani Regional Hospital between January 2011 and December 2014. This hospital was the only public health care facility available in the city and the region during the study period, thus the surveyed records represented the whole district. The Ethical Review Committee of Dr. Juan Noé Crevani Regional Hospital granted the Universidad de Tarapacá special access to historical records (resolution no. 05, MINSAL 23.01.2002) of the Ministry of Health of Chile, where open access to cancer population data has been established. A total of 108 cases were registered between 2011 and 2014; however, only 92 of them were included in this study as 16 cases had incomplete medical data. The population age ranged from 17 to 96 years, with a mean age of 59 years. Patients $\leq 15$ years were not included in the study. Patient records and information were anonymized prior to analysis, and all cases were retrieved and carefully reviewed. The data collected included details such as sex, age, date of diagnosis, type of malignancy, ethnic group, treatment, incidence, mortality and family history of hematological malignancies. Data from these records were combined into an Excel spreadsheet, and descriptive analysis was subsequently performed. The malignancies were classified according to the International Classification of Diseases for Oncology (14). The French-American-British classification system (14) was taken into consideration in the analysis of myeloid and lymphoid neoplasm $(15,16)$.

Statistical analysis. Numerical data were analyzed using Stata Statistical Software version 15.0 (StataCorp LP). Graphs show comparisons between groups as percentages. The frequency of variables was determined using Fisher's exact test and $\chi^{2}$ test. $\mathrm{P}<0.05$ was considered to indicate a statistically significant difference.

\section{Results}

A total of 108 cases of HM were registered at Dr. Juan Noé Crevani Regional Hospital between 2011 and 2014. However, only 92 of them were included in our study. Of these, 52 cases were female and 40 were male. HM distribution by type of malignancy indicated that there were 52 cases of NHL (56.5\%), 18 cases of leukemia (19.6\%), 11 cases of HL (12\%) and 11 cases of MM (12\%).

$H M$ frequency according to sex and type of malignancy between 2011 and 2014. Fig. 1A shows the frequency (\%) of HM in females and males in 2011-2014 $(\mathrm{n}=92)$. The results indicated that such frequency was non-significant in females and males in 2011, and in 2012 ( $\chi^{2}$ test, $P>0.05$ ). The distribution of HM cases varied every year between 2011 and 2014. The frequency of HL, NHL, leukemia and MM between 2011 and 2014 was assessed; the highest percentage of HL cases (45.4\%) occurred in 2012; the highest percentage of NHL cases was $30.8 \%$ in 2013; the highest percentage of leukemia cases was $33.3 \%$ in 2014; and the highest percentage of MM cases was $45.5 \%$ in 2011 (Fig. 1B). MM exhibited a progressive decrease during those years; however, no significant differences were observed $(\mathrm{P}>0.05)$. The results of the sex-based analysis indicated that HL, leukemia, and MM were more frequent in females than males (Fig. 1C). Ethnicity analysis results indicated that $83.3 \%$ of the patients were non-Aymara, whereas $16.7 \%$ were of Aymara origin; NHL was similar in Aymara and non-Aymara population (64.3 and 54.3\%, respectively) (Fig. 1D).

The results of the analysis based on age demonstrated that $21.7 \%$ of patients with HM were $>75$ years old, followed by $14.1 \%$ between 55 and 59 years old; the lowest frequency (5.4\%) was observed in the 45-49, and 70-74 years age groups (Fig. 2A). Although the highest level of occurrence of HM was observed in the $>75$ group, this result was not significant. Fig. 2B indicates that the incidence of HL was highest in the age interval 15-39, whereas MM had the highest level of occurrence in the age intervals 55-59 and $>75$ years (non-significant). Among cases of leukemia $(\mathrm{n}=18)$, ALL $(\mathrm{n}=2 ; 11.1 \%)$, CLL $(n=5 ; 27.7 \%)$, AML $(n=6 ; 33.3 \%)$, and CML $(n=5 ; 27.7 \%)$ were non-significant (Fisher's exact test; $\mathrm{P}>0.05$ ) (Fig. 2C).

Frequency of leukemia subtypes. Fig. 3 demonstrates the frequency $(\%)$ of specific types of leukemia $(n=18)$. AML $(n=6)$ was the most common subtype; however, there was no significance in the frequency of different subtypes (Fisher's exact test; $\mathrm{P}>0.05)$. Analysis based on sex revealed that the occurrences of ALL $(n=1), \operatorname{CLL}(n=3), \operatorname{AML}(n=4)$, and CML $(n=4)$ were higher in females $(50,60,66.7$, and $80 \%$, respectively) compared with those in males ALL ( $n=1)$, CLL $(\mathrm{n}=2)$, AML $(\mathrm{n}=2)$, and CML $(\mathrm{n}=1)(50,40,33.3$, and $20 \%$, respectively; Fig. 2B). According to the morphology of cell type, B-cell/small CLL, accounted for $27.8 \%(n=5)$ of such malignancies (Fig. 3C). Positive breakpoint cluster region (BCR)/ABL proto-oncogene 1 non-receptor tyrosine kinase (ABL) CML also resulted in $27.8 \%$ of cases $(n=5)$. Precursor 
A

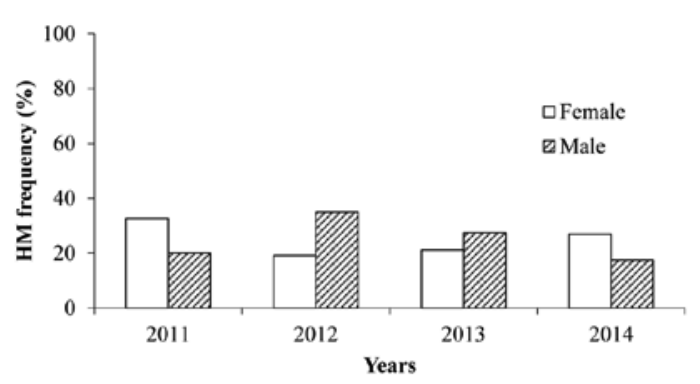

C

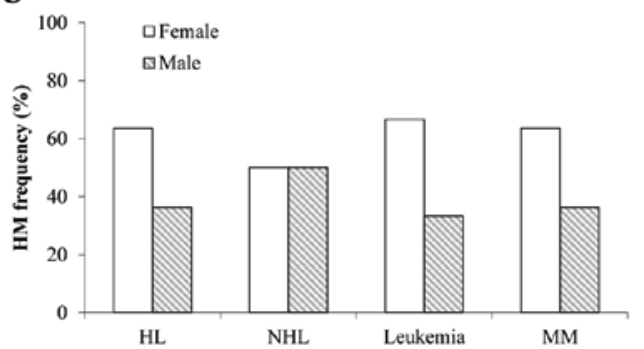

B
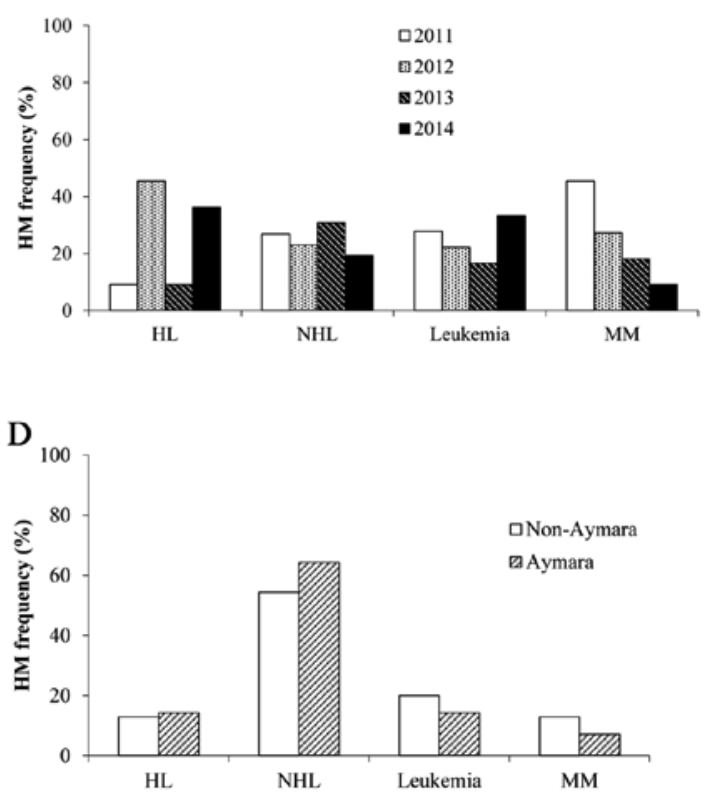

Figure 1. Frequency of HM in Arica, Chile between 2011 and 2014. (A) Frequency of HM in females and males between 2011 and 2014 (n=92). (B) HL, NHL, leukemia and MM frequency between 2011 and 2014 ( $\mathrm{n}=92$ ). MM was higher in 2011 compared with 2012, 2013 and 2014. (C) HL, NHL, leukemia and MM were higher in females compared with males. (D) NHL was similar in non-Aymara and Aymara population (n=84). HM, hematologic malignancy; HL, Hodgkin lymphoma; NHL, non-Hodgkin lymphoma; MM, multiple myeloma.

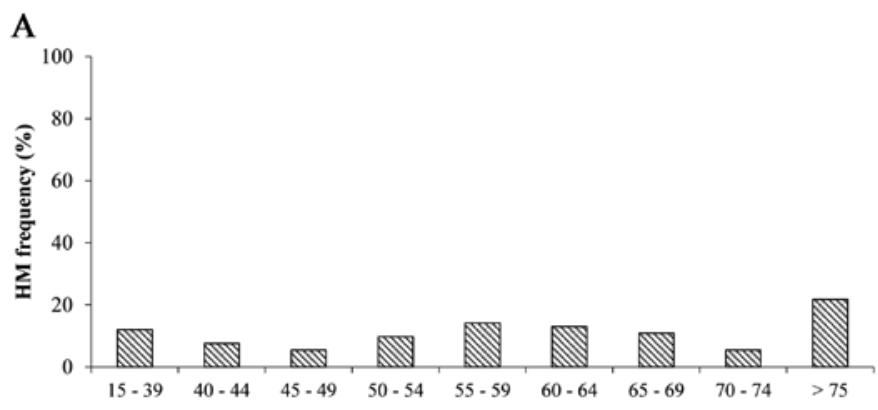

B

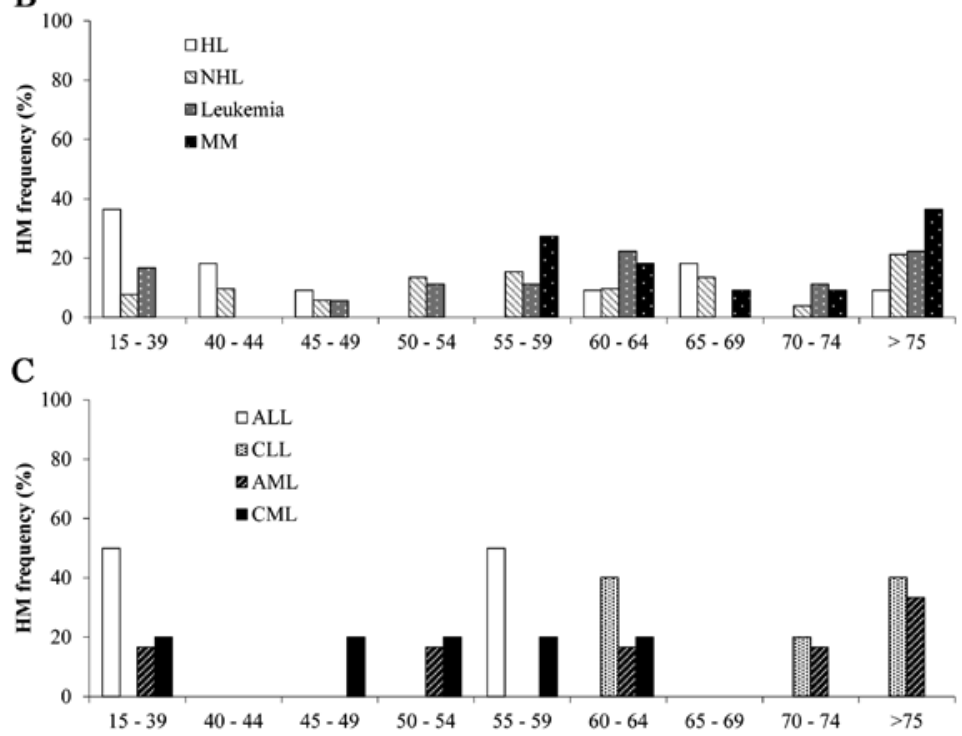

Figure 2. (A) Frequency of HM in different age groups in Arica, Chile between 2011 and 2014. HM frequency in the $>75$ years group was higher compared with other age groups. (B) Frequency of HL, NHL, leukemia and MM in different age groups (n=92). HL was higher at age intervals of 15-39 and 40-44 years compared with other HMs, whereas MM was higher at age intervals 55-59 and >75 years compared with other HMs. (C) Frequency of specific types of leukemia in different age groups $(\mathrm{n}=18)$. ALL was higher at age intervals 15-39 and 55-59 compared with CLL, AML, and CML; however, CLL incidence was higher than other diseases at age intervals 60-64 and >75 years of age. HM, hematologic malignancy; HL, Hodgkin lymphoma; NHL, non-Hodgkin lymphoma; MM, multiple myeloma; ALL, acute lymphoblastic leukemia; CLL, chronic lymphocytic leukemia; AML, acute myeloid leukemia; CML, chronic myeloid leukemia. 

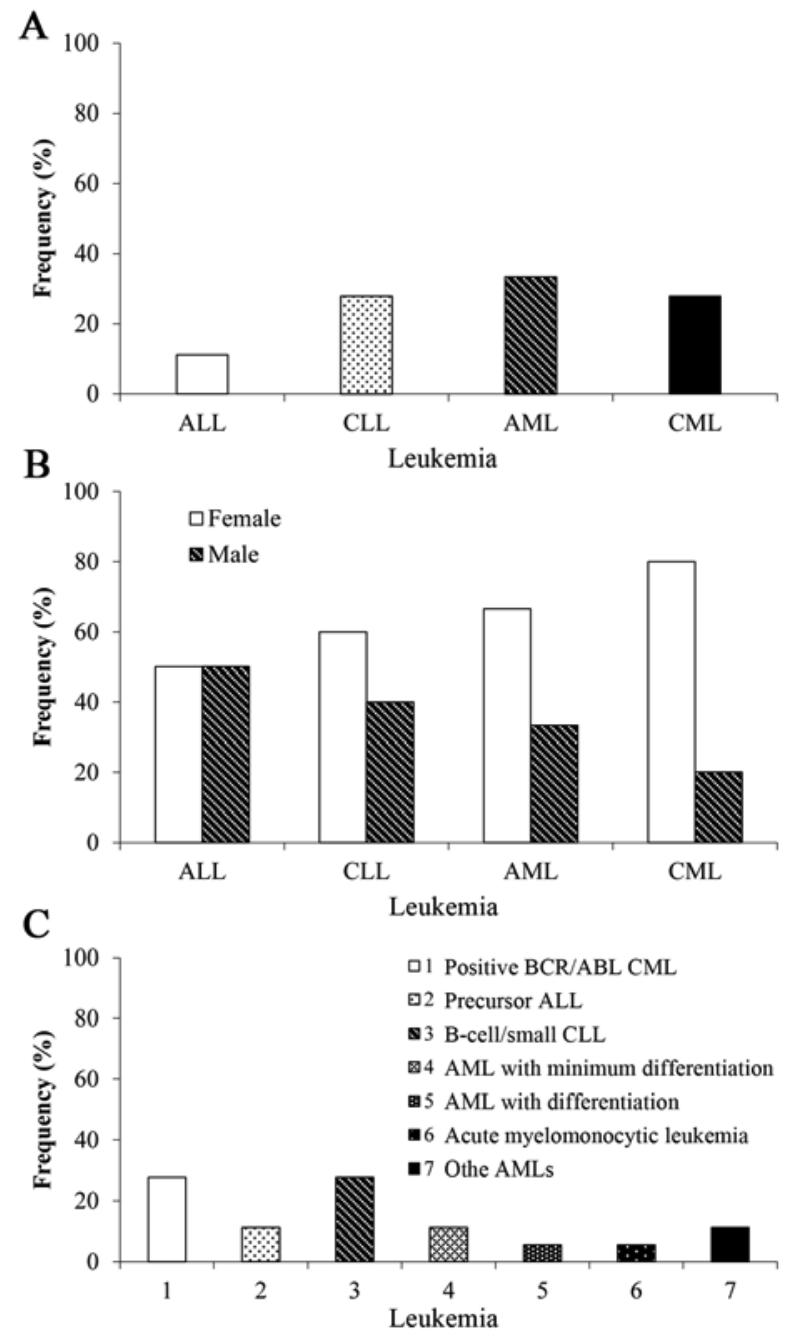

Figure 3. Frequency of different types of leukemia in Arica, Chile between 2011 and 2014. (A) AML was higher compared with ALL, CLL and CML $(\mathrm{n}=18)$. (B) CLL, AML, and CML were higher in females compared with males $(n=18)$. (C) Analysis by type of leukemia $(n=18)$. ALL, acute lymphoblastic leukemia; CLL, chronic lymphocytic leukemia; AML, acute myeloid leukemia; CML, chronic myeloid leukemia.

ALL (n=2), as well as AML with minimum differentiation (M0) $(n=2)$, each accounted for $11.1 \%$ of these malignancies. AML with differentiation (M2; $n=1)$ and acute myelomonocytic leukemia (M4; $\mathrm{n}=1$ ) accounted for only $5.6 \%$ of the cases; however, no significant differences were observed among these groups.

Lymphoma frequency according to the stage, location and characteristics of $H L$ and NHL. The frequency (\%) of lymphomas was analyzed in relation to stages of the disease ( $n=60$; Fig. 4A). The results demonstrated that the highest level of occurrence of HL was in stage II of the disease $(\mathrm{P}=0.455)$. However, NHL frequency was higher in stage IV compared with the other stages. Analysis of the nodal and extranodal location in relation to the disease indicated that HL was higher in nodal compared with extranodal lymphomas $(n=60$; Fig. 4B). The incidence of mixed cellularity was higher compared with nodular sclerosis ( $\mathrm{n}=11$; Fig. 4C), and according to morphology analysis of NHL $(n=52)$, diffuse large B-cell malignant lymphoma accounted for the highest incidence level $(n=26,50 \%)$, followed by T-cell NHL ( $n=7)$, which accounted for $13.5 \%$. Follicular lymphoma $(\mathrm{n}=5)$ and small B-cell lymphoma $(n=5)$ accounted for $9.6 \%$ each, and marginal zone B-cell $(n=3)$, Burkitt $(n=3)$, and Mantle $(n=3)$ lymphoma accounted for $5.7 \%$ each respectively (Fig. 4D).

\section{Discussion}

There is an ascendant pattern of mortality caused by cancer worldwide, which is also present in HM (1), for which the incidence rate was 7.5 per 100,000 inhabitants in Chile in 2012 (17). Age, social welfare, occupation, diet, tobacco and alcohol consumption may be determinant factors in patients with these diseases (18). Chromosomal translocations are frequently associated with a variety of cancers, especially human malignancies (19). This is the first epidemiological study on $\mathrm{HM}$ in the north of Chile $\left(18^{\circ} \mathrm{S}, 70^{\circ} \mathrm{W}\right)$, which included $\mathrm{HL}$, NHL, leukemia and MM in ninety-two patients (ages 17 and older) from Dr. Juan Noé Crevani Regional Hospital between 2011 and 2014.

The results also revealed that HM occurred more frequently in females than males in this region, which was the opposite trend to reports of HM in Eastern Morocco, the United Kingdom and France, where males exhibited a higher incidence of HM than females (20-22).

NHL and leukemia were among the fifteen most common types of cancer in Chile, whereas, HL and MM had equal incidence in 2011 to 2014 (1). Uribe Pérez et al (23) revealed that leukemia exhibited an increase in occurrence in Colombia and the Metropolitan area of Bucaramanga between 2003 and 2007. According to Miranda-Filho et al (2018), the higher incidence of ALL in parts of South America, Oceania and Europe, with markedly increased rates in Ecuador, Costa Rica and Colombia, and CLL in North America, Oceania and Asia could be markers for future research to elucidate explanatory factors that support cancer prevention (24).

The present study demonstrated that NHL was the most common type of HM accounting for $56.5 \%$ of all HM cases; this is in agreement with the Chilean national healthcare system, which reported that the most common type of lymphoma in Chile is NHL, particularly the diffuse large B-cell and follicular subtypes in young adults (15 years and older) (25). On the other hand, HL had mixed cellularity $(n=7 ; 63.6 \%)$ and nodular sclerosis $(n=4 ; 36.4 \%)$ in the present study.

There is no single known cause for blood diseases; the frequency of HM varies with geography, age and ethnicity, which suggests the involvement of various etiological factors (20). The present study revealed that HM was notably higher in non-Aymara compared with Aymara ethnic patients. There was no predisposition to hematologic diseases or data related to neoplasias such as CML, HL and ALL for this ethnic group. NHL incidence has previously been observed in all race and gender subgroups (26).

CML was first characterized by the presence of the Philadelphia chromosome (BCR/AML fusion gene), which is an acquired genetic defect in hematopoietic stem cells $(27,28)$, and $80 \%$ CML cases in females have the Philadelphia chromosome in the present study. A previous study (28) 
A

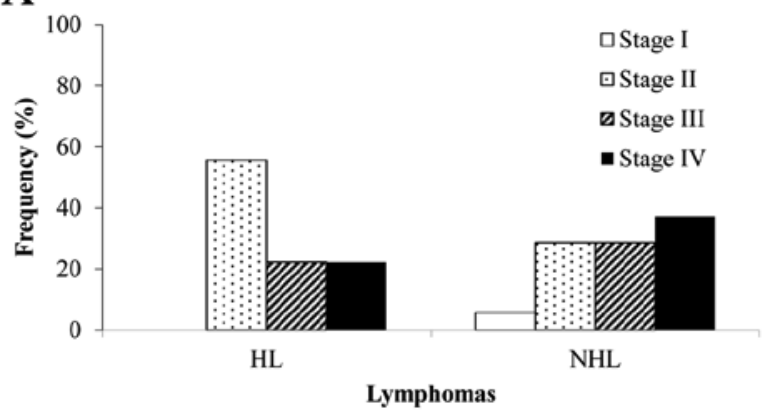

C

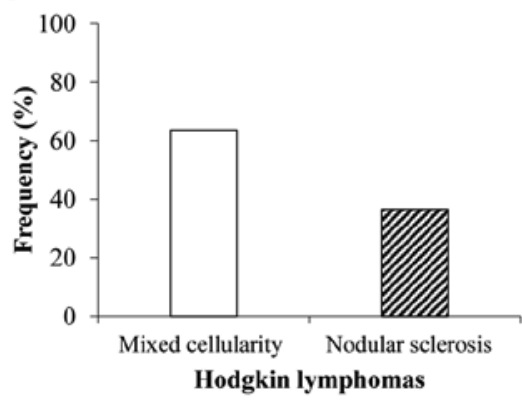

D
B

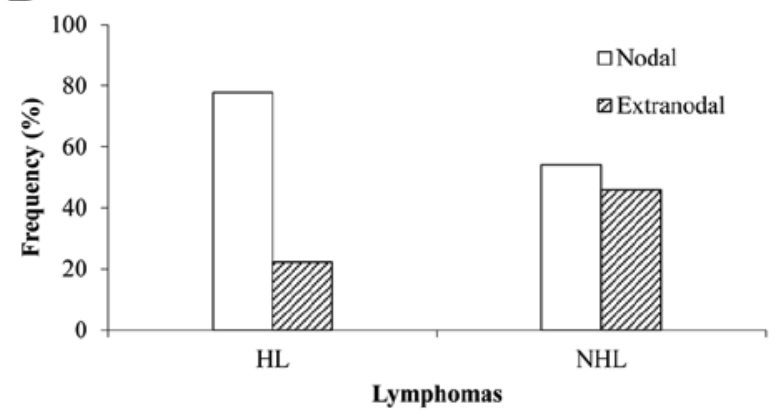

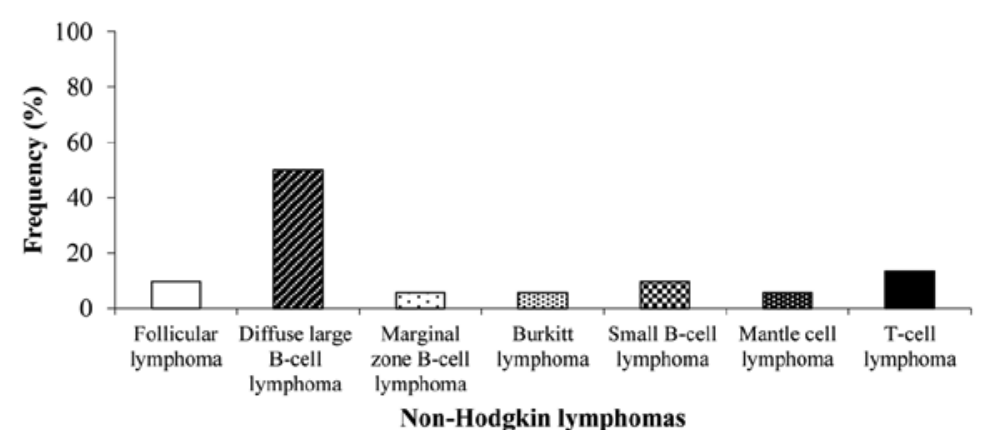

Figure 4. Frequency of lymphomas at different stages of the disease in Arica, Chile between 2011 and 2014 . (A) HL was higher in stage II compared with other stages, whereas NHL was higher in stage IV $(\mathrm{n}=60)$. (B) Nodal and extranodal location in HL and NHL. Nodal HL was more frequent compared with extranodal HL $(n=60)$. (C) Mixed cellularity HL was more frequent than nodular sclerosis (n=11). (D) NHL, specifically, diffuse large B-cell lymphoma, was more frequent than other lymphomas $(n=63)$. HL, Hodgkin lymphoma; NHL, non-Hodgkin lymphoma.

published similar findings that demonstrated that CML was BCR/ABL-positive and Elidrissi Errahhali et al (20) stated that it was present in $\sim 90 \%$ of the cases studied in Eastern Morocco. By contrast, myeloid malignancy incidence was high in the United Kingdom and Ireland between 2000 and 2002 (3). In the United Kingdom, the incidence of several myeloid and lymphoid subtypes was $>2$-fold higher in males than in females; this difference was evident in both children and adults (21).

In relation to age, as with the majority of cancers, the probability of being diagnosed with blood diseases markedly increases with age. However, unlike certain other cancers, HMs can be diagnosed at any age (20). In the present study, the incidence of HMs was highest among the elderly ( $>75$ years); however, the mean overall age at diagnosis was 59 years for all malignancies combined. HL was divided into several groups and the greatest level of occurrence was in young adults aged 15-39 years (36.4\%). NHL was present in all age groups; there was a progressive increase in the level of incidence in older adults aged 45-59, but the highest level of incidence $(21.2 \%)$ occurred in the elderly (>75) (25). A previous study carried out in Eastern Morocco indicated that HL level of occurrence was the highest in young adults aged 20-39 (31.9\%); whereas, in adults aged 40-59, NHL was predominant with $36.2 \%$ of HM cases diagnosed in this age group; in older individuals ( $>60$ years), NHL was the most common and accounted for $29.3 \%$ of HM cases (20). The results of the present study indicated that leukemia was among the most common HMs in individuals older than 60 years, and MM was most commonly noted in patients older than 55 years of age.
A low incidence rate of AML was observed in the present study. Similarly, Shysh et al (29) reported a relatively low incidence rate of AML in the Calgary Metropolitan Area, Canada; however, the age-standardized incidence rate for Canada is comparable to other epidemiological studies. In addition, the differences in population dynamics with regards to sex and age distribution may affect the incidence of AML, which has predominance in males and in the elderly (29). Similarly, Snodgrass et al (30) reported a relatively low incidence rate of new cases of ALL in the Calgary Metropolitan Area, with $>50 \%$ of cases occurring in children $<10$ years.

It was not possible to state risk factors of HM other than those reviewed and analyzed from the medical records; thus, a logistic regression model was not necessary, since the aim of this study was to analyze the frequency of hematological malignancies in the population of Arica, Chile.

In conclusion, the present study provided the pattern of $\mathrm{HM}$ distribution and frequency in the north of Chile $\left(18^{\circ} \mathrm{S}\right.$, $70^{\circ} \mathrm{W}$ ) for the first time, to the best of our knowledge. The results revealed that $\mathrm{MM}$ occurred more frequently in elderly people ( $>75$ years of age), whereas HL was more common in young adults ( $>15$ years old) compared with all other analyzed groups; however, the results exhibited no significance among any variables in this study, which might be due to the relatively small number of cases (92 for all groups). Overall, there was a progressive decrease in the occurrence of HM between 2011 and 2014, and females were more frequently affected compared with males, but the difference was not significant. In addition, increased life expectancy and improved treatment options have also led to the reduced frequency of some disorders and the predominance of others. 


\section{Acknowledgements}

The authors would like to thank Mr. Leodán A. Crispin, from Instituto de Alta Investigación, Universidad de Tarapacá, Arica, Chile for his support.

\section{Funding}

This study was supported by Universidad de Tarapacá, Arica, Chile (grant no. UTA1117).

\section{Availability of data and materials}

The datasets used and/or analyzed during the current study are available from the corresponding author on reasonable request.

\section{Authors' contributions}

GBP, KSP, MTMV and GMC designed the study and participated in interpreting the data and revising the manuscript. FCB performed statistical analysis. All authors read and approved the final manuscript.

\section{Ethics approval and consent to participate}

The retrospective data for HM were obtained between 2011 and 2014 from Dr. Juan Noé Crevani Regional Hospital, where open access to cancer population data has been established by Resolution no. 23.01.2002 of the Ministerio de Salud (Ministry of Health) of Chile.

\section{Patient consent for publication}

Not applicable.

\section{Competing interests}

The authors declare that they have no competing interests.

\section{References}

1. Ferlay J, Soerjomataram I, Dikshit R, Eser S, Mathers C, Rebelo M, Parkin DM, Forman D and Bray F: Cancer incidence and mortality worldwide: Sources, methods and major patterns in GLOBOCAN 2012. Int J Cancer 136: E359-E386, 2015.

2. Flowers CR, Glover R, Lonial S and Brawley OW: Racial differences in the incidence and outcomes for patients with hematological malignancies. Curr Probl Cancer 31: 182-201, 2007.

3. Sant M, Allemani C, Tereanu C, De Angelis R, Capocaccia R, Visser O, Marcos-Gragera R, Maynadie M, Simonetti A, Lutz JM, et al: Incidence of hematologic malignancies in Europe by morphologic subtype: Results of the HAEMACARE project. Blood 116: 3724-3734, 2010.

4. Campo E, Swerdlow SH, Harris NL, Pileri S, Stein H and Jaffe ES: The 2008 WHO classification of lymphoid neoplasms and beyond: Evolving concepts and practical applications. Blood 117: 5019-5032, 2011.

5. Vardiman JW, Thiele J, Arber DA, Brunning RD, Borowitz MJ, Porwit A, Harris NL, Le Beau MM, Hellström-Lindberg E, Tefferi A and Bloomfield CD: The 2008 revision of the World Health Organization (WHO) classification of myeloid neoplasms and acute leukemia: Rationale and important changes. Blood 114: 937-951, 2009.
6. Swerdlow SH, Campo E, Pileri SA, Harris NL, Stein H, Siebert R, Advani R, Ghielmini M, Salles GA, Zelenetz AD and Jaffe ES: The 2016 revision of the World Health Organization classification of lymphoid neoplasms. Blood 127: 2375-2390, 2016.

7. DEIS: Main causes of death, based on sex and geographical location in Chile between 1997 and 2011. DEIS Health and Information Statistics Department, Gobierno de Chile, Santiago, 2015. http://www.deis.cl/?p=2543. Accessed January 22, 2017.

8. DEIS: Adjusted mortality by malignant tumors, based on geographical location in Chile between 2000 and 2011. DEIS Health and Information Statistics Department, Gobierno de Chile, Santiago, 2015. http://www.deis.cl/?p=2543. Accessed January 22, 2017

9. DEIS: Basic Health Indicators in Chile 2013. DEIS Health and Information Statistics Department, Gobierno de Chile, Santiago, 2013. http://deis.cl/wp-content/uploads/2013/12/IBS-2013.pdf. Accessed January 23, 2017.

10. de Leeuw DC, van den Ancker W, Denkers F, de Menezes RX, Westers TM, Ossenkoppele GJ, van de Loosdrecht AA and Smit L: MicroRNA profiling can classify acute leukemias of ambiguous lineage as either acute myeloid leukemia or acute lymphoid leukemia. Clin Cancer Res 19: 2187-2196, 2013.

11. Belson M, Kingsley B and Holmes A: Risk factors for acute leukemia in children: A review. Environ Health Perspect 115: 138-145, 2007.

12. Chen J, Huang C, Zhu Y, Dong L, Cao W, Sun L, Sun H, Wan D, Liu Y, Zhang Z and Wang C: Identification of similarities and differences between myeloid and lymphoid acute leukemias using a gene-gene interaction network. Pathol Res Pract 211: 789-796, 2015 .

13. DEIS: Basic Health Indicators in Chile 2010-2014. DEIS Health and Information Statistics Department, Gobierno de Chile, Santiago, 2014. http://www.deis. cl/wp-content/uploads/2018/03/IBS-2010-2014.pdf. Accessed January 23, 2017.

14. Fritz A, Percy C, Jack A, Shanmugaratnam K, Sobin L, Parkin DM and Whelan S, (eds). International Classification of Diseases for Oncology. Third Edition edition. ICD-0, ed. Vol. 2000, World Health Organization, Malta, 247.

15. Bain BJ and Catovsky D: The leukaemic phase of non-Hodgkin's lymphoma. J Clin Pathol 48: 189-193, 1995.

16. Bennett JM, Catovsky D, Daniel MT, Flandrin G, Galton DA, Gralnick HR and Sultan C: Proposals for the classification of the acute leukaemias. French-American-British (FAB) co-operative group. Br J Haematol 33: 451-458, 1976.

17. MINSAL: Leukemia in young adults aged 15 years and over. MINSAL, Gobierno de Chile, Santiago, 2013. http://web.minsal. $\mathrm{cl} /$ sites/default/files/files/GPCLeucemiaadulto.pdf. Accessed January 28, 2015.

18. Kroll ME, Murphy F, Pirie K, Reeves GK, Green J and Beral V; Million Women Study Collaborators: Alcohol drinking, tobacco smoking and subtypes of haematological malignancy in the UK Million Women Study. Br J Cancer 107: 879-887, 2012.

19. Aplan PD: Causes of oncogenic chromosomal translocation. Trends Genet 22: 46-55, 2006.

20. Elidrissi Errahhali M, Elidrissi Errahhali M, Boulouiz R, Ouarzane $\mathrm{M}$ and Bellaoui M: Distribution and features of hematological malignancies in Eastern Morocco: A retrospective multicenter study over 5 years. BMC Cancer 16: 159, 2016.

21. Smith A, Howell D, Patmore R, Jack A and Roman E: Incidence of haematological malignancy by sub-type: A report from the haematological malignancy research network. Br J Cancer 105: 1684-1692, 2011

22. Troussard X, Duchenet V, Cornet E, Mouchel D, Malet M and Collignon A: Haematological malignancies: Incidence in Basse-Normandie, France, for 1997-2004. Rev Epidemiol Sante Publique 57: 151-158, 2009 (In French).

23. Uribe Pérez CJ, Hormiga Sánchez CM and Serrano Gómez SE: Cancer incidence and mortality in Bucaramanga, Colombia. 2008-2012. Colomb Med (Cali) 49: 73-80, 2018.

24. Miranda-Filho A, Pineros M, Ferlay J, Soerjomataram I, Monnereau A and Bray F: Epidemiological patterns of leukaemia in 184 countries: A population-based study. Lancet Haematol 5: e14-e24, 2018

25. MINSAL: Lymphoma in young adults aged 15 years and over. MINSAL, Gobierno de Chile, Santiago, 2013. http://web.minsal. cl/sites/default/files/Guia_Linfoma_adulto.pdf. Accessed January 30, 2015. 
26. Muller AM, Ihorst G, Mertelsmann $\mathrm{R}$ and Engelhardt $\mathrm{M}$ : Epidemiology of non-Hodgkin's lymphoma (NHL): Trends, geographic distribution, and etiology. Ann Hematol 84: 1-12, 2005.

27. Heisterkamp N, Stephenson JR, Groffen J, Hansen PF, de Klein A, Bartram CR and Grosveld G: Localization of the c-abl oncogene adjacent to a translocation break point in chronic myelocytic leukaemia. Nature 306: 239-242, 1983.

28. Hehlmann R, Berger U and Hochhaus A: Chronic myeloid leukemia: A model for oncology. Ann Hematol 84: 487-497, 2005.
29. Shysh AC, Nguyen LT, Guo M, Vaska M, Naugler C and Rashid-Kolvear F: The incidence of acute myeloid leukemia in Calgary, Alberta, Canada: A retrospective cohort study. BMC Public Health 18: 94, 2017.

30. Snodgrass R, Nguyen LT, Guo M, Vaska M, Naugler C and Rashid-Kolvear F: Incidence of acute lymphocytic leukemia in Calgary, Alberta, Canada: A retrospective cohort study. BMC Res Notes 11: 104, 2018. 